\title{
A review on healthcare schemes in Nigeria: A case of Corona Virus pandemic
}

\author{
TITILOPE M. DOKUNMU ${ }^{1,4 *}$., CYNTHIA U. ADJEKUKOR ${ }^{1}$, SENANU R. OKUBOYEJO ${ }^{2,4}$ AKEEM \\ BELLO $^{3,4}$, FOLUSO AYENI $^{4}$, VICTOR MBARIKA ${ }^{4}$ \\ ${ }^{1}$ Department of Biochemistry, ${ }^{2}$ Department of Computer Science, \\ Covenant University, Km 10 Idiroko road, Canaanland, Ota, NIGERIA \\ ${ }^{3}$ Department of Political Science, University of Education, Science and Technology, \\ Ikere-Ekiti, NIGERIA \\ ${ }^{4}$ International Centre for Information Technology Development \\ East Carolina University Greenville, NC, 27834, USA
}

\begin{abstract}
Healthcare is an important social amenity which impacts greatly on overall wellbeing of persons especially in low- and middle-income countries where disease burdens are high. In Nigeria health insurance schemes aim to improve the health of citizens and provide equal access to healthcare across different income classes. Corona virus pandemic has affected millions of persons globally with adverse impact on health and health expenses. In the case of a global emergency such as the Corona virus pandemic versus the normal scenario, different healthcare policies are implemented. This study reviews the challenges of health burdens, healthcare delivery, healthcare coverage before and during COVID-19 pandemic, health insurance schemes, and strategies for future improvements in Nigeria. This study reports the current state of health insurance schemes and healthcare coverage in Nigeria, during a pandemic and strategies for an all-inclusive nolicv for less nrivileged especially those managing long term illnesses. The global economic and health impact of COVID-19 is expected to be long lasting, hence health policies that further reduce hardship and health burdens are critically needed.
\end{abstract}

Keywords: social health insurance, healthcare, covid-19, public health, Nigeria.

Received: September 28, 2020. Revised: April 18, 2021. Accepted: May 4, 2021. Published: May 19, 2021.

\section{Introduction}

Corona Virus Disease (COVID-19) is ravaging the world and has affected over 153 million people and causing over 3 million deaths globally as of May 2021 [1]. COVID-19 is a viral infectious pathogen causing a global pandemic that emerged from Wuhan in China, and has spread rapidly through human-tohuman contact with still emerging information on the biology of the virus. In Nigeria, 165,167 confirmed cases of COVID-19 have been reported with 2,063 deaths as of May 3, 2021 [2]. The corona virus outbreak peaked in most western countries within 2 months of the first reported case but with slower progression in tropical low-income-countries, the highest incidence of the on-going pandemic is reported in the United States [1]. High morbidity and mortality across all age groups have been reported, with higher disparities in black and minority populations [1]. Exponential spread in America, Europe, Eastern Mediterranean, Western pacific and Southeast Asia varies paradoxically from the African region. There are various studies reporting predictions on the dynamics of the spread of the disease $[3,4]$, including models that incorporates disease susceptibility, infection rates, recovery, deaths and immunity factors to simulate the pattern of spread and impact of COVID-19 $[3,4]$. Variable transmission dynamics of COVID-19 is challenging but limiting human interactions will reduce infections and deaths rates, that can adversely affect the healthcare infrastructure of countries [3,4]. It is alarming the yet increasing rate of spread of the disease in some regions despite several mitigating strategies. After successive declines in the first and second waves, countries are experiencing increasing cases in a third wave of COVID-19 pandemic with the unprecedented cases emerging in India [1]. COVID-19 has become a global health emergency that undermines healthcare schemes available in the developed and developing countries.

The initial emergency response to the disease in different countries relied on their available healthcare 
infrastructures, however the rate of spread and management of COVID-19 quickly became overwhelming for all healthcare systems globally [1, 5-9]. Before the pandemic, cost is a major healthcare access problem; however, social health insurance (National Health Insurance scheme) is one of the schemes for improving access to good quality healthcare services. The scope of the social health insurance is designed such that it is a non-obligatory inclusion of all sectors including formal, informal, retired, and vulnerable persons in pooled partially or fully funded healthcare coverage $[2,10]$. Based on socio-economic margins and the cost of subscribing to insurance schemes, individuals opt for preferred healthcare initiatives based on affordability [11]. This study reviews the healthcare coverage before and during a pandemic in Nigeria and other countries. Nigeria bears major burdens of infectious diseases and non-communicable diseases which is also high in low- and middle-income countries [2,12], hence strengthening healthcare scheme in the country is important.

\section{Problem formulation}

This study aims to answer the two research questions which states:

"What is the state of social health insurance, healthcare benefits and quality of health in Nigeria?"

"How can health insurance schemes be made available to all to reduce burdens of disease and improve access to healthcare for all?

From 2000 to 2016 in Nigeria, cost of healthcare is largely maintained through out-of-pocket spending [13]. In 2008, a World Bank survey reported that about $0.8 \%$ of the Nigerian population was covered by national health insurance, while others access health schemes provided by employers [14-16]. Studies in Nigeria reveal that prior government spending on health is very minute compared to personal funding of healthcare [13], however, the rapid response of the government in the situation of a pandemic questions the management of healthcare delivery in Nigeria where disease burdens are high $[11,12]$. Schemes to provide good healthcare is available in Nigeria [2], but administration challenges and applicable situation makes the accruable benefits unequally accessible, based on socio-economic disparity in Nigeria. For instance, in the case of the COVID-19 pandemic in Nigeria, healthcare for those infected is being focused on while the health of persons with non-communicable diseases unrelated to COVID-19 suffered great setbacks due to the fear of spread of infection. This situation in similar globally [17]. In other regions of the world, studies have shown income level and its impact on life expectancy across the world $[13,18]$. This study reviews current status of health insurance and how it may impact the quality of life before and during a pandemic and future prospect. We reviewed literatures on social insurance schemes and healthcare coverage in countries before and during COVID-19 pandemic.

\section{Problem solution}

In a recent survey of 201 respondents composed mainly of persons aged $18-45$ years $(67.2 \%)$, versus $16.4 \%$ in $<18$ years and $16.4 \%$ in $>45$ years, $40.1 \%$ indicated subscription to a health insurance scheme, while $59.9 \%$ pay-out-of-pocket for healthcare and similar health status was reported across all age groups. In a sub-group of 180 respondents, 29 of 72 versus 20 of 108 ( $\left.\chi^{2}=10.324, p=0.002\right)$, reporting management of a medical condition subscribe to either privately purchased $(15.8 \%)$ or employer provided (48.5\%) insurance. Awareness of health insurance schemes was relatively high $73.9 \%$, but poor subscription was mostly due to perceived high cost of enrolment however $82 \%$ respondents had previously benefited from other government healthcare schemes (specifically: free mosquito net for malaria prevention) [19]. As depicted by Eteng and Agbor [20], there are various challenges that are faced by the National Health Insurance Scheme (NHIS) in Nigeria, which includes: the lack of understanding / the poor conception of what the scheme entails, the culture of the people particularly that of rural areas where sacrilegious beliefs are predominant, the incompetency of the Federal government to enforce the scheme on all sectors, prevalence of poor health facilities, less attention and care that are given to the citizens, delay in reimbursing or payment of service providers which discourages them from participating, unavailability of medical personnel in both the rural and urban areas that need access to healthcare, excessive bureaucratization of the administrative process, corruption and low participation in the scheme because of lack of awareness of the scheme.

\subsection{Review of Social Health Insurance Schemes of different countries}

A nation's first wealth is its health [15], the Healthcare sector is the major factor that determines the sustainability and feasibility of a nation's socio and economic development [21]. This is a major 
reason for the idea of a National Health Insurance Scheme (NHIS) in Nigeria, which was first considered in 1962 [22]. Nigeria is well known for funding of public health services through revenue from crude oil exports and patient user fees [23]. However, with a decline in revenues from crude oil exports in the mid-80s, which also led to a decline in financing the public health services, the solution for the Nigerian Government was to launch a National Health Insurance Scheme on the $6^{\text {th }}$ June 2005 [23]. In order to enforce the mandated provision of sound health that was made by the World health Assembly in 1998 for all people by 2000, i.e. National Economic Empowerment Development Strategy (NEEDS), the government chose National Health Insurance scheme as one of its ways to bring about improved quality health services. The NHIS is a type of Social Health Insurance (SHI) system where health services are financed through contributions to an insurance fund that the Federal Ministry of Health (the government) regulates [15]. The primary aim of the NHIS in Nigeria is to secure 'universal coverage and access to adequate and affordable healthcare to improve the health status of Nigerians especially for those participating in the various programmes / products of the scheme' [22].

The NHIS consists of one formal scheme and two informal schemes. The formal scheme, which is known as the Formal Sector Social Health Insurance Programme (FSSHIP), is funded through contributions made by both employers and employees and it covers the healthcare of the government employees and well-structured private sector [16]. The other two informal schemes are: Urban Self-Employed Social Health Insurance Programme (USSHIP) and the Rural Community Social Health Insurance Programme (RCSHIP) [16]. The NHIS is regulated at the central level by the National Health Insurance Council, and by the State Health Insurance Board (SHIB) at the state level, which is expected to enter a contract with the Primary Healthcare providers in various states [24].

Ghana adopted the National Health Insurance policy in 2003, which was later executed in 2004 but started operation in late 2005 with the primary objective of providing healthcare facilities for the larger society which will benefit her citizens. It aims to limit the amount of money spent in providing good healthcare for her citizens [25]. The National Health Insurance Authority (NHIA) that regulates the district-level mutual health insurance scheme and other health schemes oversees the activities of the NHIS in Ghana [26]. The NHIS in Ghana is responsible for both the formal and informal sector in accredited public and private facilities [27]. The formal contributions are deducted directly from source, the informal sector engage in voluntary contributions according to their socio-economic status to this group since contributions could not be forced on an individual [27].

In a study, 35\% respondents indicated the major challenge of health insurance policy is delayed service and poor treatment of patients, while $20 \%$ complained of substandard drugs [28]. Ghana NHIS is still facing some inevitable challenges since it is in its early days in achieving the goals of an SHI by increasing revenues and improving the equity and efficiency of health system [29]. In some countries like Germany, the social health insurance system was strengthened over a century, which now has global coverage for the health needs of her citizens [29]. The Tanzania insurance scheme covers over $12 \%$ of the population. There are 3 segments; the National Health Insurance Fund (NHIF) that is administered to the civil servants, the Community Health Fund (CHF) that is a non-compulsory insurance scheme, which covers mostly rural dwellers and the Tibakwa kadi (TIK), similar to the CHF but covers mainly urban dwellers [27]. A study in three African countries: Tanzania, Ghana, and South Africa showed that indirect tax, out-of-pocket payment, and health contributions from informal sector adversely affects the lower income earners but favoured the higher income earners, however the burden of illness was predominant in the low-income earners [30].

In South Africa, private insurance is responsible for about $40 \%$ of the population healthcare, with about one-sixth of the population benefiting from this scheme [27]. The scheme covers a low-level benefit package that comes with a list of severe diseases and voluntary registration [27]. It should be noted that South Africa has National Health Insurance policy on its agenda but implementation requires meeting some major prerequisites [14]. Considerations include: the relationship between the service providers and the users, the availability and cleanliness of health facilities, availability of drugs, accessibility of quality health services, the services of the public sector and the money to pay for the medical schemes [14]. All these have to be put into consideration before South Africa will be ready to change their current health system to the National Health Insurance policy.

The idea of an NHIS, which is in line with the 1978 Alma-Ata declaration of the World Health Organisation that aims to bring revolutionary changes to the health system and healthcare of people all over the universe has gained international recognition in countries like the USA, Ghana and India where convenient use of healthcare facilities 
are available as social health security programmes which is affordable [20]. The means of funding of a National Health Insurance policy differ in various countries. For example, the UK (Beveridge) National Health Service relies on general taxes, a single national risk pool and services provided for the general public that are made accessible to all while the Germany's (Bismarck) social health insurance system depends on the residents' premiums and payroll taxes, many risk pools and services are bought mostly from private providers and are made accessible to those who register [31]. The social health insurance program in India, which is known as Rashtriya Swasthya Bima Yojna (RSBY) is completely funded through general government revenues and provides unpaid care to the populace under the poverty line and has greatly expanded to provide in-patients advantages for greater than 142 million people since its commencement in 2008 [31]. Furthermore, different health insurance policy comes with different benefit. In the case of Taiwan that established its National Health Insurance (NHI) program in 1995, the benefit for insured users is greater than that of the US Medicare program [32]. Some of the benefits enjoyed from the NHI program in Taiwan includes: inpatient and ambulatory care, laboratory tests, traditional Chinese medicine, diagnostic imaging, dental care (excluding that of orthodontics and prosthodontics), medicine and selected over the counter drugs, quotidian treatment for the mentally ill, treatment for HIV/AIDS, few home healthcare, organ transplants and reliable preventive medicine (children immunizations, adult health assessments, which will include: pap smears, prenatal care and well-child check-ups) [32]. Many low- and middle-income countries struggle to finance the health sector as well as the social health insurance schemes and this contributes to increased diseases burdens in those countries including Nigeria [11-16, 29].

\subsection{Economic and health impact in countries after COVID-19 era}

Globally, the shutdown of economic activities - to practice social distancing at the initial phase of COVID-19, has impacted all aspects of life especially the economy and the already stretched healthcare systems of developed and developing countries [3-8]. The United States has estimated the economic cost of COVID at \$16 Trillion dollars and the future recovery is expected to be slow [33]. In a like manner, developing countries including Nigeria have experienced adverse socio-economic impact of COVID-19 [34,35]. The financial stress posed by the lockdown leading to economic and job losses following the pandemic further diminished the government resources in most countries with immense socio-economic impact and pressure on the health and other sectors $[3,4,36,37]$. In the aspect of health, there are unmet health needs, reduced access and quality of healthcare owing to the prolonged pressure of the pandemic on many healthcare workers which is unprecedented [8,36-38]. There are several reports of long-term complications of COVID-19 symptoms in infected persons which will increase the health burdens that will be managed by individuals afterwards [38-41]. The long-term sequelae of COVID-19 include cardiovascular, pulmonary, mental, and adverse impact on response to communicable diseases [38-41]. Hence it is crucial to improve social health insurance to provide affordable healthcare and improve lives post COVID era.

\subsection{Strategies and implementation}

Funding, structural and operational efficiencies are challenges that limit healthcare schemes in low- and middle-income countries [29], however, and in the case of COVID-19 pandemic, the crash in healthcare systems was seen globally. Countries through a private-public partnership, resuscitated the health systems and provided supplies to meet the urgent healthcare needs to combat the disease. It was reported that only $4 \%$ of Nigerians, which consists primarily of federal government employers and their households, are covered through FSSHIP health insurance scheme [42]. Current subscription rate of $40 \%$ compared to a minute rate of $0.8 \%$ reported ten years ago [15] shows much improvement and wider coverage of health insurance schemes in Nigeria. Sustainability of good healthcare delivery [10] is a major challenge that is faced by the major scheme currently. Had the government not taken care of the healthcare cost for managing COVID-19 in Nigeria, individuals will not be able to afford treatment which will negatively impact the country's health. Nigeria is not the only country faced with challenges in implementing the health insurance schemes; other countries still experience similar challenges. For example, in Ghana, the major challenged faced by NHIS are: the coverage of the scheme, the institutional framework and lack of communication, few communities' involvement, knowledge of users $[24,43]$. 


\subsection{Reducing Out-of-pocket payment}

Nigeria is a low- and middle-income country with high disease burdens [11], that greatly impact the health expenditure of most households. Catastrophic Health Expenditure (CHE), which is any money spent on healthcare in a household that in return threatens the financial capacity of the household in providing or maintaining subsistence. Cost of healthcare is largely maintained through out-ofpocket spending in most low- and middle-income countries [13-16]. Households have been forced into poverty because of the out-of-pocket payment which distinguishes a poor or rich household $[24,42,44]$. It is reported that CHE is very prevalent in poor households due to out-of-pocket payments for healthcare rather than subscription to social health insurance. The reason for this is not far fetched as social health insurance schemes are not affordable by some households. A study in Oyo state Nigeria, found that CHE was reported in $14(10.9 \%)$ of households within the minimum quintile compared to $3(2.5 \%)$ households in the maximum wealth quintile [44]. In Thailand, the annual direct costs of household ranges from $2.1 \%$ for the high-level income groups to $21.2 \%$ for the low-level income groups while it is $8 \%$ in high-level income group to $59 \%$ in the low-level income in China [14], this marginal difference in direct costs of household is one of the reasons that some individuals cannot afford social health insurance rather resort to out-ofpocket spending.

Although, CHE affects the poorer household, advocating for social health insurance will help to reduce healthcare expenses. Health expenditures and disease burdens in low resource countries are very high and poverty level is also high [11], improved government health policies and health subsidies can encourage subscription to health insurance that can limit CHE hence affordable health insurance schemes that are affordable can help reduce out-of-pocket payment and catastrophic health expenditures (CHE) faced by households [10,11]. For example, it was reported that after the commencement of health insurance in Rwanda, there was a fourfold decrease in CHE in the country [44]. In Nigeria, the percentage of out-of-pocket payment for health services is $65 \%$, which is higher than $45 \%$ reported in Ghana [22].

\subsection{Public awareness of NHIS}

It is important for the public to be aware of health scheme programs to fully benefit from them. In Nigeria, besides the Federal government, about three states adopted the FSSHIP programme after six years of its operation, they are: Cross River (2007), Bauchi (2008) and Enugu (2010) [42]. In a study conducted by Sanusi and Awe [45], a great number $(87.4 \%)$ of healthcare participants in Oyo State are aware of the NHIS and $83.2 \%$ was registered under this scheme but just $58.9 \%$ represented the number of people that benefited from this scheme [16]. Another study on the awareness of NHIS on radiographers in South East Nigeria reported a great awareness of the scheme, however some of the respondents do not participate in the scheme [23]. Another study in Osun State reported that $40 \%$ of the respondents knew about the NHIS mainly through television and billboard advertisement, but only $0.3 \%$ benefited from the scheme while $74.7 \%$ still pay out of pocket for healthcare services [21]. In another study, NHIS was seen as a scheme that will actually promote the access to better healthcare facilities but awareness is a major factor [24].

Furthermore, a study in Jasikan District of Ghana revealed that although, people might be aware of the schemes but some of the insured users are not even aware of the diseases covered by the scheme, thus educating the public can help combat this [46]. In Jasikan District in Ghana, $85.7 \%$ of the respondents reported that their awareness of the NHIS was due to public education, while $57.1 \%$ stated that promotional messages made them aware. About $42.9 \%$ versus $57.1 \%$ stated that they became aware through advertisement and sensitization programmes [46]. Some studies inferred that after the introduction of the NHIS, there was greater utilization of the health facilities. A Nigerian study showed that N357 per month was the mean cost per attendance of patients visiting the hospital before the commencement of NHIS while after the commencement of NHIS, there was a $144 \%$ increase to N870 per month for the utilization of the health services in this hospital [47]. A study of households in Oyo State, 637 (82.9\%) out of 714 households utilize the health services. In Baltimore, USA and Taiwan, there was an up-rise in the use of the nonurgent health facilities and the prenatal care services immediately after the commencement of the health insurance scheme [47]. This was also seen in North Carolina, and Minnesota, USA where the visits of publicly insured children to the emergency room increased whereas in Jordan, utilization of curative care significantly increased [47].

\subsection{Healthcare system Infrastructures}

The responsiveness of insured users in NHIS in Nigeria was examined in a study considering different that determine how the insured users will utilize the health facilities. Based on prompt attention 
(which include the short waiting period of insured users to access rapid care), dignity domain (receiving care in a respective way), the availability of basic quality health facilities, involving the insured users in decision making concerning their health status, private providers treated the users better than public providers [48]. A study of rural household use of healthcare facilities in Osun State Nigeria, revealed that available health facilities were very poor, awareness and understanding of the scheme and the utilization of the health facilities were dependent on a number of factors which include: the amount to be paid for registration and contribution quota made to the scheme, the number of times each household fall ill, the workability and the coverage of the scheme. Furthermore, satisfaction from the available health facility and scheme led to underutilization of the program, reduced productivity among employees and poor health status [49]. In a study from University College Hospital, Ibadan, it was shown that $48.6 \%$ of the $82 \%$ responses rate had poor knowledge of the scheme while the remaining $51.4 \%$ have a good knowledge of the scheme, $42 \%$ and $20 \%$ of the respondents evaluated the services of NHIS as good while $48.6 \%$ were pleased with the services given by the NHIS [49]. In another study in the Jasikan District in Ghana, subscribers to the scheme were not pleased by the services given by the scheme in the following ways: $69.1 \%$ expressed dissatisfaction in customer service, while $58.6 \%$ expressed concerns about services covered by the scheme, $87.8 \%$ in payment of claims and $71.4 \%$ in the professionalism of the staff [46] while another study revealed that the NHIS has provided availability of healthcare facilities to their population than those who could afford good healthcare, leading to both increase in out-patient and in-patient utilisation of the health facilities. From their results, the total number of active subscribers of the scheme increased from 8.16 million in 2010 to 8.23 million in 2011 , a $0.8 \%$ increase in outpatient's utilization, the increases were from 0.6 million in 2005 to 16.9 million in 2010 and 25.5 million in 2011 [25]. Another study of the NHIS scheme in Ghana reported $66.4 \%$ of the populace benefiting from the scheme and $29.6 \%$ in the informal adult sector [16]. Another study in Ghana showed that there is no equity in the enrolment in NHIS, the poorer household have a lower enrolment in the scheme than the richer households $[26,50]$.

\section{Conclusion}

The global economic and health impact of COVID19 is expected to be long lasting, based on this, policies that address the after effects to further reduce hardship and health burdens are needed in all countries [51]. Government policies that support health equality is crucial in improving the overall health of a nation. In the situation of the current Corona virus disease (COVID-19) pandemic, Nigeria and other nations initiated immediate health interventions/policies that provided health coverage for all COVID-19 admitted patients under the Control of Infectious Disease Act. Improving the social health insurance schemes will be needed by most countries to manage the long-term health burdens that COVID-19 would cause. This executive health bill was enacted in 2020 to cover cost, care and effective management of persons infected with the disease. The National Centre for Disease Control under this healthcare funding continues to respond to the public health challenge of the rising cases of COVID-19 [12]. From December 2020, vaccines that prevent COVID-19 infection were developed and rolled out to reduce the global pandemic. A total of $1,188,839$ COVID-19 vaccine doses have been administered in Nigeria as of May 3, 2021 [2]. This is administered free of charge and irrespective of social insurance in all countries. The response of the Nigerian government has been commended on combating the COVID-19 disease despite persisting health scheme problems in the country [52] and this should be maintained postCOVID. Other government policies including the Millennium Development Goals 4 and 5, achieve health coverage by providing pregnant women a complete access to antenatal, prenatal and postnatal care e.g. as in Ghana [28]. Although there are Federal and State government subsidized health schemes like free malaria drugs for pregnant women and children $<5$ years [15], only a small fraction of the population benefit from these schemes because they are not widely accessible hence, out of pocket payment is still a common practice in Nigeria.

The NHIS was created to provide access to adequate and affordable healthcare for all the citizens in Nigeria, but the aim of the scheme has not been fully achieved. The need for equal access to the basic healthcare should be considered for every individual regardless of economic status to promote good welfare of the nation [45] including addressing low participation due to awareness, requiring employers to provide health insurance for their employees [24] among others. In places of low utilization of the healthcare facilities especially in the rural areas where poor health facilities are prevalent [49], improving the access to a better healthcare facility or improving the already available healthcare facilities in the rural areas will help to improve the utilization 
of the facilities in the rural households and in turn improve their health welfare. Also, much attention should be given to the rural areas, as they are the ones that face more health challenges due to poor facilities, poverty and limited health personnel.

\section{Author Contribution}

All authors contributed to the writing and review of this manuscript.

\section{Acknowledgements}

We acknowledge the Covenant University Centre for Research Innovation and Discovery (CUCRID), Nigeria for funding the publication of this research.

\section{References}

[1] Corona virus. https://www.worldometers.info/coronavirus/

[2] Nigeria Centre for Disease Control. https://covid19.ncdc.gov.ng/report/

[3] Rattanakul, C., \& Lenbury, Y. Model analysis and simulation on impacts of COVID-19 pandemic on the economy: a case study of Thailand's GDP and its lock down measures, International Journal of Biology and Biomedical Engineering, 14, 2020, 180-190.

[4] Alsaeed, N. I., Alqaissi, E. Y., \& Siddiqui, M. A. An Agent-based Simulation of the SIRD model of COVID-19 Spread. International Journal of Biology and Biomedical Engineering, 14, 2020, 210-217.

[5] Frawley, T. van Gelderen, F., Somanadhan, S., Coveney, K., Phelan, A., Lynam-Loane, P., \& De Brun, A. The impact of COVID-19 on health systems, mental health and the potential for nursing. Ireland Journal of Psychology and Medicine, 16, 2020, 1-7

[6] Wong, S. Y. S., Zhang, D., Sit, R. W. S., Yip, B. H. K., Chung, R. Y., Wong, C. K. M., Chan, D. C. C., Sun, W., Kwok, K. O., \& Mercer, S. W. Impact of COVID-19 on loneliness, mental health, and health service utilisation: a prospective cohort study of older adults with multimorbidity in primary care. British Journal of General Practice, 70, 700, 2020, e817-e824.

[7] Bauchner, H., \& Fontanarosa, P. B. Excess Deaths and the Great Pandemic of 2020. Journal of the American Medical Association, 324, 15, 2020, 1504-1505.

[8] Nuzzo, J. B., Bell, J. A., \& Cameron, E. E. Suboptimal US Response to COVID-19 Despite Robust Capabilities and Resources. Journal of the American Medical Association, 324, 14, 2020, 1391-1392

[9] Centre for Disease Control. Reduced access to care - Household Pulse Survey 2021. https://www.cdc.gov/nchs/covid19/pulse/reduc ed-access-to-care.htm. (Accessed May 2021)

[10] Osibogun, A., Dokunmu, O. O. K., Onajole, A. T., Bassi, P., Ibraheem, T., Okonkwo, I. P., Alayande, R. A., \& Jibowu, O. L. Community Organizations: Do they make any difference to healthcare in Nigeria? Nigerian Journal of Community Medicine \& Primary Health Care, 13, 2001, 53-60.

[11] World Health Organization, "Global report on diseases," World Health Organization, Geneva, 2016.

[12] National Health Insurance Schemes. https://www.nhis.gov.ng/objectives-of-thescheme/ (Accessed May 2018)

[13] Institute for Health Metrics and Evaluation (IHME). Health-related SDGs. Seattle, WA: IHME, University of Washington, 2017. Available from http://www.healthmetricsandevaluation.or g (Accessed July 2017)

[14] McIntyre, D., Goudge, J., Harris, B., Nxumalo, N., \& Nkos, M. Prerequisites for national health insurance in South Africa: results of a national household survey. SAMJ: South African Medical Journal, 99, 10, 2009, 725-729.

[15] Olakunde, B. Public health care financing in Nigeria: Which way forward? Annals of Nigerian Medicine, 6, 1, 2012, 4-10.

[16] Odeyemi, I. A. Community-based health insurance programmes and the national health insurance scheme of Nigeria: challenges to uptake and integration. International Journal for Equity in Health, 13, 1, 2014, 20.

[17] Centre for Disease Control. Health insurance coverage - Household Pulse Survey 2021. https://www.cdc.gov/nchs/covid19/pulse/health -insurance-coverage.htm. (Accessed May 2021)

[18] United Nations World Population Prospect. https://www.un.org/development/desa/publicati ons/world-population-prospects-the-2017revision.html

[19] Dokunmu, T. M., Adjekukor, C. U., Oladejo, D. O., Amoo, E. O. Dataset on analysis of quality of health and social insurance subscription in different socio-economic class of workers in selected areas in southwest Nigeria. Data in Brief, 21, 2018, 1286-1291.

[20] Eteng, F. O., \& Ijim-Agbor, U. Understanding the challenges and prospects of administering the national health insurance scheme in Nigeria. 
International Journal of Humanities and Social Science Research, 2, 8, 2016, 40-48.

[21] Olugbenga-Bello, A. I., \& Adebimpe, W. O. Knowledge and attitude of civil servants in Osun state, Southwestern Nigeria towards the national health insurance. Nigerian Journal of Clinical Practice, 13, 4, 2010, 421-426.

[22] Odeyemi, I., \& Nixon, J. Assessing equity in health care through the national health insurance schemes of Nigeria and Ghana: a review-based comparative analysis. International Journal for Equity in Health, 12, 1, 2013, 9.

[23] Okaro, A. O., Ohagwu C. C., Njoku J. Awareness and perception of national health insurance scheme (NHIS) among radiographers in south east Nigeria. American Journal of Scientific Research, 8, 2010, 18-25.

[24] Ibiwoye, A., \& Adeleke, I. A. Does National Health Insurance Promote Access to Quality Health Care? Evidence from Nigeria. The Geneva Papers on Risk and Insurance - Issues and Practice, 33, 2, 2008, 219-233.

[25] Owusu-Sekyere, E., \& Bagah, D. A. Towards a sustainable health care financing in Ghana: is the national health insurance the solution? Public Health Research, 4, 5, 2014, 185-194.

[26] Blanchet, N. J., Fink, G., \& Osei-Akoto, I. The effect of Ghana's National Health Insurance Scheme on health care utilisation. Ghana Medical Journal, 46, 2, 2012, 76-84.

[27] Macha, J., Harris, B., Garshong, B., Ataguba, J. E., Akazili, J., Kuwawenaruwa, A., \& Borghi, J. Factors influencing the burden of health care financing and the distribution of health care benefits in Ghana, Tanzania and South Africa. Health Policy and Planning, 27(suppl_1), 2012, i46-i54.

[28] Siaw, N. A., \& Kwofie, S. Assessment of the Effects of the Free Maternal Health Policy on Maternal Health: A Case Study of New Juaben Municipality, Koforidua, Ghana. International Journal of Business and Social Research, 6, 7, 2016, 51-62.

[29] Witter, S., \& Garshong, B. Something old or something new? Social health insurance in Ghana. BMC International Health and Human Rights, 9, 1, 2009, 20.

[30] Mills, A., Ataguba, J. E., Akazili, J., Borghi, J., Garshong, B., Makawia, S., McIntyre, D. Equity in financing and use of health care in Ghana, South Africa, and Tanzania: implications for paths to universal coverage. The Lancet, 380, 9837, 2012, 126-133.

[31] Lagomarsino, G., Garabrant, A., Adyas, A., Muga, R., \& Otoo, N. Moving towards universal health coverage: health insurance reforms in nine developing countries in Africa and Asia. The Lancet, 380, 9845, 2012, 933-943.

[32] Cheng, T.-M. Taiwan's new national health insurance program: genesis and experience so far. Health Affairs, 22, 3, 2003, 61-76.

[33] Cutler, D. M., \& Summers, L. H. The COVID19 Pandemic and the \$16 Trillion Virus. Journal of the American Medical Association, 324, 15, 2020, 1495-1496

[34] Adam, C., Henstridge, M., \& Lee, S. After the lockdown: macroeconomic adjustment to the COVID-19 pandemic in sub-Saharan Africa. Oxford Review of Economic Policy, 36, Supp1, 2020, S338-S358.

[35] UNDP. The impact of the covid-19 pandemic in Nigeria - a socio-economic analysis. Annual publication of UNDP, 2020. https://www.ng.undp.org/content/nigeria/en/ho me/library/the-impact-of-the-covid-19pandemic-in-nigeria--a-socio-economic.html (Accessed May 2021).

[36] Kong, Y-C., Sakti, V-V., Sullivan, R., \& BhooPathy, N. Cancer and COVID-19: economic impact on households in Southeast Asia. eCancer, 14, 2020, 1134

[37] Chang, A. Y., Cullen, M. R., Harrington, R. A., \& Barry, M. The impact of novel coronavirus COVID-19 on noncommunicable disease patients and health systems: a review. Journal of Internal Medicine, 289, 4, 2021, 450-462.

[38] Jefferies, S., French, P., Gilkison, C., Graham, G., Hope, V., Marshall, J., McElnay, C., McNeil, A., Muellner, P., Paine, S., Prasad, N., Scott, J., Sherwood, J., Yang, L., \& Priest, P. COVID-19 in New Zealand and the impact of the national response: a descriptive epidemiology study. The Lancet Public Health 5, 11, 2020, E612-E623

[39] Carfi, A., Bernabei, R., Landi, F., \& Gemelli Against COVID-19 Post-Acute Care Study Group. Persistent Symptoms in Patients After Acute COVID-19. Journal of the American Medical Association, 324, 6, 2020, 603-605.

[40] Garrigues, E., Janvier, P., Kherabi, Y., Le Bot, A., Hamon, A., Gouze, H., Doucet, L., Berkani, S., Oliosi, E., Mallart, E., Corre, F., Zarrouk, V., Moyer, J. D., Galy, A., Honsel, V., Fantin, B., \& Nguyen, Y. Post-discharge persistent symptoms and health-related quality of life after hospitalization for COVID-19. Journal of Infection, 81, 6, 2020, e4-e6.

[41] Halpin, S. J., McIvor, C., Whyatt, G., Adams, A., Harvey, O., McLean, L., Walshaw, C., 
Kemp, S., Corrado, J., Singh, R., Collins, T., O'Connor, R. J., \& Sivan, M. Postdischarge symptoms and rehabilitation needs in survivors of COVID-19 infection: A cross-sectional evaluation. Journal of Medical Virology, 93, 2, 2021, 1013-1022.

[42] Onoka, C. A., Onwujekwe, O. E., Uzochukwu, B. S., \& Ezumah, N. N. Promoting universal financial protection: constraints and enabling factors in scaling-up coverage with social health insurance in Nigeria. Health Research Policy and Systems, 11, 1, 2013, 20.

[43] Addae-Korankye, A. Challenges of financing health care in Ghana: the case of national health insurance scheme (NHIS). International Journal of Asian Social Science, 3, 2, 2013, 511-522.

[44] Ilesanmi, O. S., Adebiyi, A. O., \& Fatiregun, A. A. National health insurance scheme: how protected are households in Oyo State, Nigeria from catastrophic health expenditure? International Journal of Health Policy and Management, 2, 4, 2014, 175-180.

[45] Sanusi, R. A., \& Awe, A. T. An assessment of awareness level of national health insurance scheme (NHIS) among health care consumers in Oyo State, Nigeria. The Social Sciences, 4, 2, 2009, 143-148.

[46] Danku, L. S., Adade, T. C., Dodor, C. T., \& Lapon, J. M. Evaluation of National Health Insurance Scheme (NHIS) Policy on The Health Care Delivery In Ghana. EPRA International Journal of Research and Development (IJRD), 2, 3, 2017, 126-145.

[47] Akande, T., Salaudeen, A., \& Babatunde, O. The effects of national health insurance scheme on utilization of health services at Unilorin Teaching Hospital staff clinic, Ilorin, Nigeria. Health Science Journal, 5, 2, 2011, 98-106.

[48] Mohammed, S., Bermejo, J. L., Souares, A., Sauerborn, R., \& Dong, H. Assessing responsiveness of health care services within a health insurance scheme in Nigeria: users' perspectives. BMC Health Services Research, 13, 2013, 502.

[49] Gbadamosi, I. A., \& Famutimi, E. O. Perception and Satisfaction of Employees with National Health Insurance Scheme Services: A Descriptive Study at University College Hospital, Ibadan, Nigeria. International Journal of Tropical Disease \& Health, 22, 1, 2017, 112.

[50] Jehu-Appiah, C., Aryeetey, G., Spaan, E., de Hoop, T., Agyepong, I., \& Baltussen, R. Equity aspects of the National Health Insurance Scheme in Ghana: Who is enrolling, who is not and why? Social Science \& Medicine, 72, 2, 2011, 157-165.

[51] Chudik, A., Mohaddes, K., Pesaran, M. H., Raissi, M., \& Rebucci, A. Economic consequences of Covid-19: A counterfactual multi-country analysis, 2020. Available at https://voxeu.org/article/economicconsequences-covid-19-multi-country-analysis. (Accessed May 2021).

[52] Adepoju, P. Nigeria responds to COVID-19; first case detected in sub-Saharan Africa. Nature Medicine 26, 2020, 444-448.

\section{Creative Commons Attribution License 4.0 (Attribution 4.0 International, CC BY 4.0)}

This article is published under the terms of the Creative Commons Attribution License 4.0 https://creativecommons.org/licenses/by/4.0/deed.en_US 